p-ISSN: 2503-1392

e-ISSN: 2620-5424

\title{
HUBUNGAN DUKUNGAN SUAMI PADA IBU HAMIL TERHADAP KUNJUNGAN ANTENATAL CARE (ANC) DI BPM SORAYA PALEMBANG
}

\author{
RELATIONSHIP SUPPORT RELATIONSHIPS TO PREGNANT WOMEN TO ANTENATAL \\ CARE (ANC) VISITS AT BPM SORAYA, PALEMBANG
}

\author{
Aryanti $^{1}$, Karneli $^{2}$, Sella Citra Pratiwi ${ }^{3}$ \\ Sekolah Tinggi Ilmu Kesehatan Abdurahman Palembang, Jl.Sukajaya No.7 Kol.H.Burlian KM 5,5, Palembang, \\ Sumatera Selatan \\ email: ${ }^{1}$ aryantianti89@gmail.com., ${ }^{2}$ karnelilanang@gmail.com, ${ }^{3}$ shellacitra1320@gmail.com
}

\begin{abstract}
ABSTRAK
Masa kehamilan merupakan status kesehatan ibu hamil yang dapat diketahui dengan pemeriksaan diri dan kehamilannya kepelayanan kesehatan terdekat yang disebut Antenatal care (ANC) perawatan sebelum masa persalinan atau perawatan pada ibu hamil. ANC adalah pemeriksaan kehamilan untuk mengoptimalkan kesehatan mental dan fisik ibu hamil. Dengan demikian mampu menghadapi persalinan, kala nifas, pemberian ASI, dan kembalinya kesehatan reproduksi secara wajar. Pemeriksaan ANC adalah pemeriksaan kehamilan yang dilakukan untuk pemeriksaan ibu dan janin secara berkala, yang diikuti dengan upaya koreksi terhadap penyimpangan yang ditentukan. Penelitian ini bertujuan untuk mengetahui hubungan dukungan suami pada ibu hamil terhadap kunjungan ANC di BPM Soraya Palembang. Jenis penelitian ini menggunakan kualitatif yang bersifat deskriptif dengan desain penelitian crosss sectional dengan uji Chi-square dengan signifikan $\alpha=0,05$ sampel 25 orang ibu hamil. Pada penelitian ini didapatkan hasil ibu yang mendapatkan dukungan suami sebanyak 23 responden (92\%), sedangkan ibu yang tidak mendapatkan dukungan suami sebanyak 2 responden (8\%) dan Ibu yang melakukan kunjungan ANC baik sebanyak 23 responden (92\%), sedangkan yang tidak baik melakukan kunjungan ANC sebanyak 2 responden (8\%). Analisa data menggunakan analisa univariat dan bivariate. Hasil uji statistika didapatkan hasil $\rho$ value 0,000 . Kesimpulan adanya hubungan dukunga suami pada ibu hamil terhadap kunjungan ANC di BPM Soaraya Palembang 2019.
\end{abstract}

Kata Kunci : Kunjungan Antenatal Care (ANC), Dukungan Suami.

\section{ABSTRACT}

The period of pregnancy is the health status of pregnant women which can be determined by examining and pregnancy at the closest health service called Antenatal care (ANC) pre-delivery care or care for pregnant women. ANC is a pregnancy to optimize the mental and physical health of pregnant women. Thus being able to deal with childbirth, during childbirth, breastfeeding, and returning to health naturally. Antenatal care examination is a pregnancy that is performed for periodic examination of the mother and fetus, followed by correction of deviations. The pregnancy period is the health status of pregnant women which can be known by examining their pregnancy checks at the nearest health service called ANC care before delivery or care for pregnant women. Antenatal care (ANC) is a pregnancy to optimize the mental and physical health of pregnant women. An antenatal care examination is a pregnancy performed for periodic examination of the mother and fetus, which is followed by corrective action against the prescribed. The purpose of this study was to determine the correlation between husband supports in pregnant women on the Antenatal Care (ANC) visit at Private Midwifery Palembang. This study used qualitative descriptive research with a sectional cross-sectional design. The significant result with the Chi-square test was $\alpha=0.05$. The sample was 25 pregnant mothers. In this study, the results of mothers who received husband support were 23 respondents (92\%), while mothers who did not receive husband support were 2 respondents (8\%). Mothers who had good Antenatal Care visits were 23 respondents (92\%), while those who were not good at conducting Antenatal Care visits were 2 respondents (8\%). Data analysis used univariate and bivariate analysis. The statistical test results obtained $\rho$ value $=0,000$. It could be concluded that there was a significant correlation between husband's support for pregnant mothers and ANC visit in 2019 at Private Midwifery Palembang.

Keywords : : Antenatal Care Visit (ANC), Husband Support 


\section{PENDAHULUAN}

Kehamilan sebagai fertilisasi atau penyatuan dari spermatozoa dan ovum serta dilanjutkan dengan nidasi atau implantasi. Bila dihitung dari saat fertilisasi hingga bayi lahir, kehamilan normal akan berlangsung dalam waktu 40 minggu atau 9 bulan menurut kalender internasional. Lama kehamilan berlangsung sampai persalinan aterm (cukup bulan) adalah sekitar 280 sampai 300 hari. Kehamilan dibagi menjadi tiga triwulan, yaitu triwulan pertama ( 0 sampai 12 minggu), triwulan kedua (13 sampai 28 minggu), dan triwulan ketiga (29 sampai 42 minggu $)^{1}$.

Masa kehamilan, status kesehatan ibu hamil dapat diketahui dengan pemeriksaan diri dan kehamilannya kepelayanan kesehatan terdekat yang disebut ANC perawatan sebelum masa persalinan atau perawatan pada ibu hamil. Antenatal care (ANC) adalah pemeriksaan kehamilan untuk mengoptimalkan kesehatan mental dan fisik ibu hamil. Dengan demikian mampu menghadapi persalinan, kala nifas, pemberian ASI, dan kembalinya kesehatan reproduksi secara wajar. Pemerikasaan antenatal care adalah pemeriksaan kehamilan yang dilakukan untuk pemeriksaan ibu dan janin secara berkala, yang diikuti dengan upaya koreksi terhadap penyimpangan yang ditentukan. Perawatan kehamilan adalah perawatan yang ditujukan kepada ibu hamil, yang bukan hanya apabila ibu sakit dan memerlukan perawatan, melainkan juga pengawasan dan penjagaan wanita hamil agar tidak terjadi kelainan sehingga mendapatkan ibu dan anak sehat ${ }^{1}$.

ANC bertujuan untuk memantau kemajuan ibu selama kehamilan, mengenali secara dini adanya ketidaknormalan atau komplikasi yang mungkin terjadi selama hamil, mempersiapkan persalinan cukup bulan, serta mempersiapkan peran ibu dan keluarga dalam menerima kelahiran bayinya agar dapat tumbuh kembang secara normal ${ }^{1}$.

Pemeriksaan ANC terdapat jadwal kunjungan yang mana kunjungan I pada usia kehamilan 16 minggu, kunjungan II pada usia kehamialn 24-28 minggu, kunjungan III dan kunjungan IV pada usia kehamialn 32-36 minggu. Kunjungan ibu hamil selama kehamilan terdapat 4 kali kunjungan untuk memenuhi standar pemeriksaan $\mathrm{ANC}^{1}$.

Pemeriksaan kehamilan ada faktor-faktor yang mempengaruhi ibu hamil dalam memeriksakan kehamilanya yaitu ekonomi, letak geografis, sosial budaya, dan dukungan suami) ${ }^{2}$.

Dampak dari ibu yang tidak sesuai melakukan pemeriksaan sesuai anjuran bidan, maka resiko tidak dapat dideteksi secara dini dan rujukan pun terlambat dilakukan, sehingga ibu dan bayi tidak dapat ditangani secara maksimal. Maka dari itu kunjungan ANC sangatlah di wajibkan untuk mendeteksi secara dini adakah komplikasi yang terjadi dan suami diharuskan untuk mendampingi ibu pada saat pemeriksaan. Yang mana dukungan suami merupakan suatu bentuk perwujudan dari sikap perhatian dan kasih sayang. Suami memiliki andil yang cukup besar dalam menentukan status kesehatan ibu. Dukungan suami yang baik dapat memberikan motivasi yang baik pada ibu untuk memeriksakan kehamilannya ${ }^{3 .}$

Suami dan keluarga apabila tidak mendukung dengan penuh kehamilan, dikhawatirkan ibu tidak dapat beradaptasi dengan baik mengenai ketidaknyamanan kehamilan. Untuk mengurangi resiko pada kehamilan yang disebabkan kurangnya dukungan keluarga maka setidaknya tercipta komunikasi yang baik khususnya dengan pasangan, keluarga, teman. Komunikasi atau hubungan emosional yang baik akan membantu menghadapi kesulitan dan kesedihan. Berdasarkan hal tersebut janin dapat mengalami keterhambatan perkembangan atau gangguan emosi saat lahir jika stres ibu tidak tertangani, oleh karena itu dukungan keluarga khususnya suami mempunyai andil yang besar dalam menemukan status kesehatan ibu. Untuk lebih mengoptimalkan ketepatan jadwal kunjungan ANC maka penerapan kelas ibu hamil dan penyuluhan secara rutin sangat diperlukan ${ }^{3}$.

Dukungan suami merupakan suatu bentuk perwujudan dari sikap perhatian dan kasih sayang. Dukungan dapat diberikan baik secara fisik maupun psikis. Suami memiliki andil yang cukup besar dalam menentukan status kesehatan ibu. Dukungan suami yang baik dapat memberikan motivasi yang baik pada ibu untuk memeriksakan kehamilannya. Dukungan suami dalam pelayanan ANC dapat ditunjukkan dengan memberikan kasih sayang dan perhatian kepada istri, mendorong dan mengantar istri untuk memeriksakan kehamilan ke fasilitas pelayanan kesehatan terdekat, memenuhi kebutuhan gizi, membantu menentukan tempat persalinan (fasilitas kesehatan) serta mempersiapkan biaya persalinan. Suami adalah orang pertama dan utama dalam memberi dorongan kepada istri sebelum pihak lain turut memberi dorongan, dukungan dan perhatian seorang suami terhadap istri yang sedang hamil yang akan membawa dampak bagi sikap bayi ${ }^{4}$.

Menurut Hubungan Dukungan Suami Dengan Kepatuhan Pemeriksaan Antenatal Care Pada Ibu Hamil Di Puskesmas Kasih II Bantul Yogyakarta. Penelitian ini dilakukan di Puskesmas Kasih II Bantul pada tanggal 06 Juni-19 Juli $2017^{5}$. Subyek penelitian ini adalah semua ibu hamil yang berkunjung ke Puskesmas Kasih II Bantul sebanyak 79 responden. 
Peneliti mengunakan kuisioner pada responden yg telah dipilih dengan kriteria inklusi dan eksklusi yang telah diterapkan oleh peneliti. Hasil penelitian ini menunjukan bahwa responden yang memiliki dukungan suami dalam kategori cukup sebanyak 55 responden ( 69,6\%), sedangkan responden yang mendapatkan dukungan suami dalam kategori kurang sebanyak 3 orang responden $(3,8 \%)$.

Dukungan suami dinyatakan berhubungan secara statistik dengan kepatuhan pemeriksaan ANC yang ditunjukkan dengan hasil uji ststistik Chi-square diperoleh nilai $\rho$ - Value $0,014(\rho<0,05)$ dimana $\mathrm{H}_{\mathrm{O}}$ ditolak dan $\mathrm{H}_{\mathrm{a}}$ diterima, sehingga dapat disimpulkan bahwa ada hubungan dukungan suami dengan kepatuhan pemeriksaan ANC di Puskesmas Kasih II Bantul Yogyakarta.

Menurut penelitian ${ }^{6}$ Berdasarkan tujuan penelitian metode penelitian yang digunakan adalah metode penelitian kuantitatif. Penelitian kuantitatif adalah penelitian yang mengambil sampel dari suatu populasi dan menggunkan kuesioner sebagai alat pengumpulan data yang pokok. Rancangan dalam penelitan ini menggunakan desain Analitik dengan pendekatan CrossSectional. Desain penelitian ini bertujuan untuk mencari hubungan dukungan suami terhadap keteraturan kunjungan Antenatal Care pada ibu hamil di Puskesmas Wates Lampung Tengah tahun 2014. Bahwa dari hasil uji statistic chi square di dapat nilai $p$ value $<$ dari $\alpha(0,000<0,05)$.

Artinya Ho ditolak dapat di simpulkan adahubungan dukungan suami dengan kunjungan Antenatal Care pada ibu hamil di PuskesmasWates Lampung Tengah Tahun 2014. ORdidapat 36,42 yang berarti responden yangkurang mendapat dukungan suami memilikipeluang tidak teratur melakukan Antenatal Care sebesar 36,42 kali di bandingkanresponden yang mendapat dukungan suami.

\section{METODE PENELITIAN}

Tabel 1 Distribusi Frekuensi Dukungan Suami di BPM Soraya Palembang Tahun 2019
Menurut jenis penelitian ini menggunakan kualitatif yang bersifat deskriptif dengan tujuan untuk melihat gambaran hubungan anatara variabel satu dengan variabel lain, rancangan penelitian ini menggunakan pendekatan cross sectional yaitu mempelajari dinamika kolerasi antara faktor-faktor pengaruh dalam waktu yang sama.

Populasi adalah keseluruhan objek dalam penelitian yang kita lakukan. Populasi dalam penelitian ini adalah seluruh ibu hamil yang berjumlah 30 orang di BPM Soraya Palembang tahun 2019. Sampel adalah sebagian yang diambil dari populasi sampel dalam penelitian ini adalah ibu hamil yang memenuhi kritereria inklusi.Tehnik pengambilan sampel dalam penelitian ini menggunakan Non Probabiliti sampling dengan metode Purposive Sampling, berjumlah 25 orang.

Adapun kriteria inklusi pada sampel penelitian ini adalah :

a) Ibu hamil trimester III

b) Ibu hamil yang bersedia menjadi responden

c) Ibu hamil yang melakukan kunjungan ANC

Adapun kriteria eksklusi pada sampel penelitian ini adalah :

a) Ibu hamil trimester I dan II

b) Ibu hamil yang tidak bersedia menjadi respnden

c) Ibu hamil yang tidak melakukan kunjungan ANC

\section{HASIL PENELITIAN}

\section{Analisis Univariat}

Dukungan suami, Pada penelitian ini dukungan suami dibagi menjadi dua kategori yaitu mendukung apabila responden menjawab pertanyaan dengan nilai $\geq 75 \%$ dan tidak mendukung apabila responden menjawab pertanyaan dengan nilai $\leq 75 \%$ yang mana dapat dilihat pada tabel 1dibawah ini

\begin{tabular}{lccc}
\hline No & Dukungan Suami & Frekuensi (n) & Presentase (\%) \\
\hline 1 & Mendukung & 23 & 92 \\
2 & Tidak Mendukung & 2 & 8 \\
\hline & Jumlah & $\mathbf{2 5}$ & $\mathbf{1 0 0}$
\end{tabular}


CENDEKIA MEDIKA

2020 p-ISSN: 2503-1392

e-ISSN: 2620-5424
Berdasarkan pada Tabel 1 dapat dilihat bahwa dari 25 responden ibu yang mendapat dukungan suami sebanyak 23 responden (92\%), sedangkan ibu yang tidak mendapat dukungan suami sebanyak 2 responden $(8 \%)$.

\section{kunjungan Antenatal Care (ANC)}

Pada penelitian ini kunjungan Antenatal Care dibagi menjadi dua kategori yaitu baik jika melakukan kunjungan Antenatal Care sesuai standar dan tidak baik jika melakukan kunjungan Antenatal Care tidaksesuai standar, dapat dilihat pada tabel 2 di bawah ini

Tabel 2 Distribusi Frekuensi Berdasarkan Kunjungan Antenatal Care di BPM Soraya Palembang Tahun 2019

\begin{tabular}{llll}
\hline No & Kunjungan Antenatal Care & Frekuensi (n) & Presentase (\%) \\
\hline 1 & Baik & 23 & 92 \\
2 & Tidak Baik & 2 & 8 \\
\hline & Jumlah & $\mathbf{2 5}$ & $\mathbf{1 0 0}$ \\
\hline
\end{tabular}

Berdasarkan pada tabel 2 dapat dilihat bahwa dari 25 responden yang melakukan kunjungan Antenatal Care baik sebanyak 23 responden $(92 \%)$, sedangkan yang tidak baik melakukan kunjungan Antenatal Care sebanyak 2 responden $(8 \%)$.

\section{Analisis Bivariat}

Penelitian ini dilakukan untuk mengetahui hubungan dukungan suami terhadap kunjungan Antenatal Care pada ibu hamil yang dapat dilihat pada tabel 3 dibawah ini

Tabel 3 Hubungan Dukungan Suami pada Ibu Hamil Terhadap Kunjungan Antenatal Care di BPM Soraya Palembang

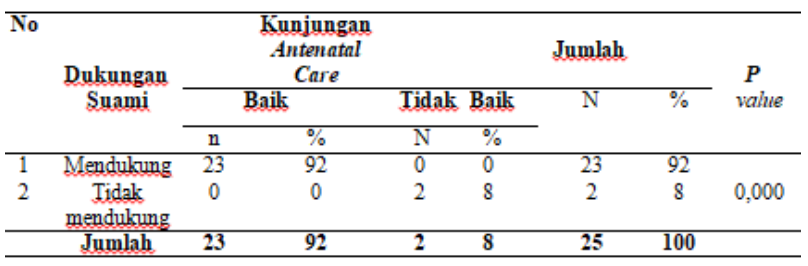

Berdasarkan Tabel 3 dapat diketahui bahwa dari 25 responden yang melakukan kunjungan Antenatal Care baik dengan dukungan suami yang mendukung sebanyak 23 responden $(92 \%)$ sedangkan yang melakukan kunjungan Antenatal Care tidak baik dengan dukungan suami tidak mendukung sebanyak 2 responden $(8 \%)$.

Berdasarkan uji statistic Chi-Square dengan tingkat kepercayaan $95 \%$ dan tingkat kemaknaan $\alpha=0,05$ didapatkan $\rho$ value $=0,000<\alpha 0,05$ hal ini menjelaskan bahwa ada hubungan yang signifikan (bermakna) antara dukungan suami dengan kunjungan Antenatal Care.

\section{PEMBAHASAN}

\section{Dukungan Suami}

Berdasarkan hasil analisis univariat dari 25 responden ibu yang mendapatkan dukungan suami sebanyak 23 responden $(92 \%)$, sedangkan ibu yang tidak mendapatkan dukungan suami sebanyak 2 responden (8\%). Penelitian ini selaras dengan penelitian (Rury Narulita Sari), berdasarkan hasil penelitian menunjukkan bahwa ibu yang mendapat dukungan suami sebanyak 32 orang $(78,1 \%)$ dan yang tidak mendapat dukungan suami sebanyak 9 orang $(21,9 \%)$. Dukungan suami merupakan suatu dukungan yang di berikan secara emosional dalam bentuk perhatian, memberikan dukungan penghargaan dalam bentuk pujian, memberikan informasi tentang pentingnya, kunjungan Antenatal Care, dan memberikan dukungan fisik dengan mengantar ibu melakukan kunjungan Antenatal Care, sehingga ibu termotivasi untuk melakukan kunjungan Antenatal Care secara teratur (Sari and Kusparlina, 2017).

Sesuai teori (Notoatmodjo, 2010) dukungan suami dalam pelayanan Antenatal Care dapat ditunjukkan dengan memberikan kasih sayang dan perhatian kepada istri, mendorong dan 
CENDEKIA MEDIKA

2020 p-ISSN: 2503-1392

e-ISSN: 2620-5424 mengantar istri untuk memeriksakan kehamilan ke fasilitas pelayanan kesehatan terdekat, mengingatkan istri untuk periksa hamil, memberikan arahan tentang pentingnya periksa hamil, memenuhi kebutuhan gizi, membantu menentukan tempat persalinan (fasilitas kesehatan) serta mempersiapkan biaya persalinan. dimana dukungan suami terhadap istri dalam masa kehamilan dapat meningkatkan kesiapan ibu dalam menghadapi masa kehamilan.

Dukungan suami yang baik dapat memberikan motivasi yang baik pada ibu untuk memeriksakan kehamilannya. Menurut 2 suami yang memberikan dukungan pada istri pada masa kehamilan diantaranya yaitu memberikan tindakan dan respon positif terhadap keluhan istrinya, memberikan rasa aman, dan ibu merasa terjaga, memberikan bantuan bila istri membutuhkan dan bersedia meluangkan waktu untuk keperluan ibu.

Peneliti dapat berasumsi bahwa dukungan suami sangat penting bagi ibu hamil. Dengan adanya dukungan ibu termotivasi menjaga kehamilannya.

\section{Kunjungan Antenatal Care (ANC)}

Berdasarkan hasil analisis univariat dari 25 responden ibu yang melakukan kunjungan Antenatal Care baik sebanyak 23 responden (92\%), sedangkan ibu yang melakukan kunjungan Antenatal Care tidak baik sebanyak 2 responden $(8 \%)$.

Berdasarkan diatas menyatakan bahwa kunjungan Antenatal Care baik lebih banyak dari pada kunjungan Antenenatal Care yang tidak baik. Penelitian ini selaras dengan penelitian (Wulandari, 2017) berdasarkan hasil penelitian menunjukkan bahwa di Puskesmas Kasihan II Bantul Yogyakarta dari 79 responden yang diteliti, didapatkan bahwa sebagian besar responden patuh dalam kunjungan pemeriksaan ANC di Puskesmas yaitu sebanyak 74 responden $(93,7 \%)$

Sesuai teori Salmah (2013), Antenatal Care Sesuai standar apabila melakukan kunjungan minimal 4 kali kunjungan yang mana pada TM I dengan usia kehamilan 16 minggu melakukan kunjungan 1 kali, TM II dengan usia kehamilan 24-28 minggu melakukan kunjungan 1 kali, TM III dengan usia kehamilan 32-36 mingu melakukan kunjungan 2 kali atau pada TM II dengan usia kehamilan 24-28 minggu melakukan kunjungan 2 kali, TM III dengan usia kehamilan 32-36 mingu melakukan kunjungan 2 kali. Di mana masa kehamilan merupakan saat yang terbaik untuk mempersiapkan kehadiran bayi dan untuk mempersiapkan diri sebagai calon orang tua. Sehingga selama hamil, calon ibu harus memeriksakan dirinya dan kesehatan janin dalam kandungan secara teratur.

Menurut(1) tujuan antenatal care yaitu memantau kemajuan kehamilan untuk memastikan kesehatan ibu dan tumbuh kembang bayi, meningkatkan dan mempertahankan kesehatan fisik, mental dan sosial ibu serta bayi, mengenali secara dini adanya ketidaknormalan atau komplikasi yang mugkin terjadi selama hamil, termasuk riwayat penyakit secara umum, kebidanan, dan pembedahan, mempersiapkan persalinan cukup bulan, melahirkan dengan selamat, ibunya maupun bayinya terutama semaksimal mumgkin, mempersiapkan ibu agar masa nifas berjalan dengan normal dan pemberian asi eksklusif, dan mempersiapkan peran ibu dan keluarga dalam menerima kelahiran bayinya agar dapat tumbuh kembang secara normal.

Dengan demikian peneliti dapat berasumsi jika ibu hamil melakukan kunjungan Antenatal Care dengan baik, sangat bermanfaat bagi ibu hamil, dimana dengan melakukan kunjungan secara rutin dapat mengetahui perkembangan ibu dan janin, dan dapat mendeteksi secara dini adakah komplikasi yang terjadi selama kehamilan.

\section{Hubungan Dukungan Suami pada Ibu Hamil Terhadap Kunjungan Antenatal Care}

Berdasarkan hasil analisis bivariat dari 25 responden ibu yang mendapatkan dukungan suami, lebih besar dari ibu yang tidak mendapatkan dukungan suami. Hasil uji statistika menunjukkan bahwa ada hubungan yang signifikan (bermakna) antara dukungan suami dengan kunjungan Antenatal Care. Penelitian ini selaras dengan penelitian (Mulyati Lia, Mudrikatun \& Sawitry 2010) dengan hasil ada hubungan antara dukungan suami pada ibu hamil dengan kunjungan ANC. 
CENDEKIA MEDIKA

2020 p-ISSN: 2503-1392

e-ISSN: 2620-5424
Volume 5 Nomor 2, September
Antenatal Care yang dilakukan ibu hamil di pengaruhi oleh beberapa faktor seperti pengetahuan, sikap, tingkat pendidikan, paritas, pekerjaan, status ekonomi, dukungan suami dan kualitas pelayanan Antenatal Care. Salah satu faktor ibu melakukan kunjungan Antenatal Care yaitu dukungan suami. dimana pemeriksaan kehamilan dapat ditingkatkan dengan adanya dukungan suami. Dukungan suami mempunyai peran yang sangat besar menentukan keberhasilan Antental Care karena kondisi fisik maupun psikis ibu hamil akan turut menetukan keteraturan Antenatal Care.

Menurut (Tura, 2007) mengungkap Antenatal Care yang dilakukan ibu hamil di pengaruhi oleh beberapa faktor seperti pengetahuan, sikap, tingkat pendidikan, paritas, pekerjaan, status ekonomi, dukungan suami dan kualitas pelayanan Antenatal Care. Salah satu faktor ibu melakukan kunjungan Antenatal Care yaitu dukungan suami.

Menurut (Indrayani, 2011) Antenatal care adalah pemeriksaan kehamilan sebagai pengawasan sebelum persalinan terutama ditujukan pada pertumbuhan dan perkembangan janin dalam rahim, dimana pemeriksaan kehamilan dapat ditingkatkan dengan adanya dukungan suami.

Menurut $^{7}$ salah satu faktor penguat yang mempengaruhi kepatuhan ibu hamil dalam melakukan kunjungan ANC iyalah dukungan suami, yang mana suami sebagai calon seorang ayah, sikap suami terhadap ibu hamil, yang dalam hal ini adalah istrinya, sangat menentukan rasa sayangnya terhadap kesehatan istri dan calon anaknya. Melalui dukungan suami yang baik sebagai pendamping terdekat ibu, semakin tinggi dorongan yang didapatkan ibu hamil untuk menjaga kehamilannya, sehingga ibu termotivasi untuk melakukan kunjungan ANC.

Suami dapat berperan aktif dalam keberhasilan Antenatal Care dengan jalan memberikan dukungan secara emosional dan bantuan-bantuan praktis lainnya. Seperti mengantar ibu kunjungan Antenatal Care ketempat pelayanan kesehatan, memberikan motivasi, memberikan informasi pentingnya melakukan kunjungan Antenatal Care. Pengertian tentang peranan suami merupakan langkah pertama bagi seorang suami untuk dapat mendukung ibu agar teratur melakukan kunjungan antental care (Mulyati Lia, Mudrikatun \& Sawitry 2010).
Dukungan suami adalah suatu dukungan yang diberikan oleh suami pada istrinya yang sedang hamil dalam hal ini dukungan tersebut bisa dalam bentuk verbal dan non verbal, saran, bantuan yang nyata berupa tingkah laku atau kehadiran yang dapat memberikan keuntungan emosional dan dapat mempengaruhi tingkah laku istrinya yang dalam hal ini adalah dukungan untuk melakukan kunjungan ANC (Mufdilah, 2009).

Faktor-faktor yang mempengaruhi dukungan suami Menurut ${ }^{2}$ menyimpulkan beberapa faktor yang mempengaruhi dukungan suami dalam perlindungan kesehatan reproduksi istri (ibu), antara lain adalah budayaDiberbagai wilayah di Indonesia terutama di dalam masyarakat yang masih tradisioanal (Patrilineal), menganggap istri adalah konco wingking, yang artinya bahwa kaum wanita tidak sederajat dengan kaum pria, dan wanita hanyalah bertugas untuk melayani kebutuhan dan keinginan suami saja. Anggapan seperti ini mempengaruhi perlakuan suami terhadap kesehatan reproduksi istri. Pendapatan Pada masyarakat kebanyakan, $75 \%-100 \%$. penghasilanya dipergunakan untuk membiayai keperluan hidupnya. Sehingga pada akhirnya ibu hamil tidak mempunyai kemampuan untuk membayar. Secara konkrit dapat dikemukakan bahwa pemberdayaan suami perlu dikaitkan dengan pemberdayaan ekonomi keluarga sehingga kepala keluarga tidak mempunyai alasan untuk tidak memperhatikan kesehatan istrinya. Tingkat Pendidikan Tingkat pendidikan akan mempengaruhi wawasan dan pengetahuan suami sebagai kepala rumah tangga. Semakin rendah pengetahuan suami maka akses terhadap informasi 20 kesehatan istrinya akan berkurang sehingga suami akan kesulitan untuk mengambil keputusan secara efektif.

Suami merupakan bagian dari keluarga, maka dukungan suami dapat diperlukan dalam menentukan berbagai kebijakan dalam keluarga. Dukungan merupakan salah satu faktor penguat yang dapat mempengaruhi seseorang dalam berprilaku. Ibu yang tidak mendapatkan dukungan suami akan berperilaku kurang memperdulikan kehamilannya dengan tidak melakukan kunjungan Antenatal Care secara teratur, hal ini disebabkan karena ibu tidak memiliki dorongan yang memotivasi, tidak mendapat perhatian secara emosional, tidak mendapat informasi dari suami tentang manfaat Antenatal Care. Hal ini menyebabkan perilaku ibu dalam melakukan Antenatal Care lebih dominan dipengaruhi oleh 
CENDEKIA MEDIKA

2020 p-ISSN: 2503-1392

e-ISSN: 2620-5424 kesadaran ibu yang dapat menyebabkan kesadaran ibu menjadi rendah maka kunjungan Antenatal Care tidak teratur (Manuaba, 2010).

Dengan demikian peneliti dapat berasumsi bahwa suami yang memberikan dukungan yang baik, ibu akan termotivasi dan kedaan psikologis tidak terganggu, karena dengan adanya dukungan suami, maka ibu hamil akan lebih menjaga kehamilannya dan memanfaatkan kunjungan Antenatal Care dengan rutin dan baik, jika ibu tidak mendapat dukungan suami, maka ibu tidak mendaptkan motivasi untuk melakukan kunjungan Antenatal Care secara teratur, sehingga tidak dapat dilakukan deteksi dini terhadap komplikasi ibu dan janin Karena beberapa suami berasumsi meskipun tidak teratur melakukan kunjungan Antenatal Care pada anakanak sebelumnya tidak ada yange mengalami gangguan kesehatan baik saat kehamilan ataupun persalinan.

\section{KESIMPULAN}

Kunjungan Antenatal Care baik sebanyak 23 responden (92\%), lebih besar dari kunjungan yang tidak baik sebanyak 2 responden $(8 \%)$. Dukungan suami sebanyak 23 responden (92\%), lebih besar dari yang tidak mendapatkan dukungan suami sebanyak 2 responden (8\%). Ada hubungan yang signifikan (bermakna) dukungan suami dengan kunjungan Antenatal Care.lebih besar dari yang tidak mendapatkan dukungan suami sebanyak 2 responden $(8 \%)$. Ada hubungan yang signifikan (bermakna) dukungan suami dengan kunjungan Antenatal Care.

\section{SARAN}

Bagi Mahasiswi Menambah pengetahuan dan informasi bahwa dukungan suami sangat penting bagi ibu hamil sehingga termotivasi dan lebih teratur melakukan kunjungan Antental Care. Bagi Lahan Praktek Diharapkan kepada lahan praktek untuk dapat melaksanakan dan memanfaatkan pentingnya dukungan suami pada ibu hamil terhadap kunjungan Antenatal Care.

\section{DAFTAR PUSTAKA}

1. Kumalasari and Intan (2015) Panduan Praktik Laboratorium dan Klinik Perawatan
Antenatal, Postnatal Bayi Baru Lahir dan Kontrasepsi. Jakarta: Salemba Medika.

2. Bobak, Lowdermilk and Jensen (2004) Keperawatan Maternitas. Jakarta: EGC.

3. Maulana, Heri and D.J (2009) Promosi Kesehatan. jakarta: EGC.

4. Dagun, M. (2002) psikologi keluarga. Jakarta: Rineka Cipta.

5. Wulandari, Dwi, Meirita. (2017) 'Hubungan Dukungan Suami Dengan Kepatuhan Pemeriksaan Antenatal Care Pada Ibu Hamil Di Puskesmas Kasih II Bantul Yogyakarta'.

6. Evayanti, Yulistiana (2015) 'Hubungan Pengetahuan Ibu Dan Dukungan Suami Pada Ibu Hamil Terhadap Keteraturan Kunjungan Antenatal Care (ANC) Di Puskesmas Wates Lampung Tengah Tahun 2015 Jurnal Kebidanan.

7. Sari and Kusparlina. (2017). Asuhan Kebidanan Antenatal. Jakarta: EGC.

8. Notoatmodjo (2010) Metode Penelitian Kesehatan. Jakarta : Rineka Cipta.

9. Mulyati Lia, Mudrikatun and Sawitry. (2010) 'Hubungan Dukungan Suami Pada Ibu Hamil Dengan Kunjungan Anc di Rumah Bersalin Bhakti IBI jl. Sendangguwo baru v no 44c Kota Semarang'.

10. Tura (2007) Asuhan Kebidanan (Kehamilan). Yogyakarta : Nuha Medika.

11. Indrayani. (2011) Buku Ajar Asuhan Kehamilan. Jakarta : Trans Info Medika.

12. Rukiyah a Ai Yeyeh (2013) Asuhan Kebidanan Pada Masa Kehamilan. Jakarta: Trans Info Medika.

13. Mufdillah (2009) Panduan Asuhan Kebidanan Ibu Hamil. Yogyakarta : Nurhamedika.Manuaba. (2010). Ilmu kebidanan, penyakit Kadungan adan KB. Jakarta : Buku Kedokteran EG 